\title{
Development of Toilet Air Quality Assessment and Monitoring System
}

\author{
Ronald James A. Basan ${ }^{1}$, Kevin T. Arizobal ${ }^{1}$, Naomi Claire T. Obas ${ }^{1}$, Rodrigo S. Pangantihon Jr. ${ }^{2}$ \\ ${ }^{1,2}$ Computer Engineering Program, College of Engineering Education \\ University of Mindanao, Matina, Davao City, Philippines \\ ${ }^{1}$ ronaldjamesbasan15@gmail.com \\ ${ }^{1}$ karizobal114@gmail.com \\ 1namyyclaire@gmail.com \\ ${ }^{2}$ rodrigo_pangantihon@umindanao.edu.ph
}

\begin{abstract}
Indoor Air Quality inside public toilets significantly impacts the toilet users; therefore, maintaining good indoor air quality is necessary. This study aims to create a system that would give a real-time assessment of air quality inside the toilet and notify the toilet attendants of its status. It also seeks to recognize the toilet attendant who attended it at a specific time. Materials like MQ135 sensor, RFID, and Arduino UNO Microcontroller gathered air samples and toilet attendants' logins. Wireless local area network transmitted the collected data to the server. The collected air data are being measured and compared to the standards from the statutory offices. With the confusion matrix principle, the system has reached $100 \%$ accuracy for the toilet attendant recognition, $91.11 \%$ for the air quality monitoring, and $93.33 \%$ for the notification.
\end{abstract}

Key words : Indoor air quality, toilet, Arduino UNO, MQ135, RFID

\section{INTRODUCTION}

Indoor Air Quality (IAQ) is the air quality inside buildings and structures that plays an essential role in the occupants' health and comfort. A toilet is an indoor facility that is frequently used by people. Therefore, it is vital to maintain good air quality to keep it hygienic and sanitary. Air is the easiest way for microbes and airborne bacteria to disseminate, which causes significant environmental problems, particularly in public areas such as toilets. A toilet that has terrible air quality is dirty. Most facilities have a public toilet attendant that maintains cleanliness in public restrooms. These public toilet attendants follow the schedule in cleaning the toilets. However, there are times when public restrooms need cleaning even if it is not yet the cleaning schedule because it gives discomfort to the users.

A study shows that most of the population devote much of their time indoors. Air quality inside close facilities has a secure link to lung health. Bad indoor air quality results in some severe health problems which are not readily identified [1]. The last 30 years' reports affirm that indoor air quality dramatically impacts convenience, safety, health, and well-being and efficiency. The major contributing factors to this are pervasive, both indoor pollutants and ever-increasing indoor sources [2]. A research performed in some motor parks around Owerri, Nigeria, showed that the indoor environment of the toilet facilities was not hygienic and may present danger to travelers before they embarked on their journey [3]. A cheap monitoring device can be used and can provide an accurate risk management evaluation. Indeed, indoor air quality may be extremely diverse from the anticipated value of the living environment [4]. Toilet flushing causes airborne bacteria emission, which results in bad air quality and spread of disease to children and the elderly [5]. The provision of good indoor air quality in classrooms and other buildings is very critical. A bad indoor air quality can impact the safety of the inhabitants' health and contribute to decreased efficiency or poor academic results. A study conducted in school buildings has resulted in a weak air quality report in these buildings and that measures are needed to improve it within the facilities [6]. Internal air quality within academic institutions is a significant discussion in building and health study. Absences and weak school habits are linked to bad air quality in classrooms [7]. A multidisciplinary group conducted and proposed a stepwise approach to assess and manage indoor air quality. It is to integrate surveys that cover perceived indoor air quality, symptoms, and psychological work aspects. The proposed approach used to map indoor air quality to deal with problems related to it. [8].

An air pollution control network was built to track and evaluate air quality in real time and report data to a central server, holding the data up to date. The measures of air quality obtained by the machine are correct and analyzed using Microsoft Excel [9]. With Arduino microcontroller, Wireless Sensor Network (WSN), and GSM technology, monitoring of dangerous gasses was enhanced and taken into grave account. Alert message and a buzzer also considered related actions. [10]. Utilization of IoT technology improves the process of air monitoring with the help of MQ135, which senses the gas and 
Arduino as the heart that controls the entire process. The Automatic Air \& Sound management system is a step toward contributing a solution to the most significant threat in the air using uSense. This cost-effective, interactive tracking method allows real-time understanding of the amounts of polluting gasses in various areas of the region. The findings are aligned with the local government regulation agency which demonstrate that USense will be helpful to air quality. [12]. The Internet of Things is already being used widely in every industry and performs a key function in air quality monitoring system. Together with a Raspberry Pi, better data processing and distribution are now offered [13]. The issue of poor air quality has been debated in mainstream media so often in recent years, with growing urgency. Measuring stations and specially purchased and installed sensors are used to track different characteristics of air quality. A web application was designed to get reports of real- time air quality in a city. Web services and various sources, such as informative websites and specialized sensors, gather data [14]. A three-phase air quality control system has been placed in order to fix the issues of the new surveillance technology. Things like Arduino, wifi module, and gas sensors built the IoT (Internet of Things) package. An android application has also enabled users to access the data. The air pollution kit helped a person recognize, monitor, and quantify air pollution. It dramatically helps people, particularly those suffering from respiratory diseases [15]. A portable low-cost air pollution was successfully developed with the correct calibration and settings. It uses a sampling mechanism with its sensors to gather air pollutants for measurement and a GPS sensor for location tagging. It was a developed with a web app interface for tracking purposes. The system shows that it is capable of monitoring air pollutants possibly at a fraction of the cost [16]. A functional model which is a progression of Recurrent Neural Network and Long Short-Term Memory network was built to predict concentration of air pollutants in Indian cities. It takes meteorological data like temperature, wind speed and direction, and relative humidity for the accurate prediction. With the help of RNN and LSTM, pollutants' prediction was achievable [17].

The findings of the studies conducted inferred that odor gasses are one of the main problems within the toilet and could affect user health. Most of the time, indoor air quality should be better. User's satisfaction in using the restrooms must be measured to have proper management in the toilet. Part of maintaining a user-friendly comfort station is to have an appropriate maintenance team. Attendants should make sure that they attend at a particular time and if it is necessary. All of the gathered information motivates the conduct of the study.

The study's objective is to design and implement an air quality assessment device and use an air quality sensor, microcontroller, and wireless signal transmitter. Another aim was to create a system that would notify public toilet attendants when the public toilet is dirty and produce lousy air quality. That would give a real-time assessment of the air quality in the toilets. The study also aims to recognize the attendant who attended the toilet at a specific time.

This study aims to evaluate the indoor air quality of public toilets in actual time with fair accuracy. This project is significant because it helps maintain the cleanliness and the excellent air quality in public restrooms by notifying the public toilet attendants when it is time for cleaning. With the use of newly affordable technologies like microcontrollers and gas sensors, maintaining the cleanliness and the excellent air quality in the public toilet can be achieved. It makes the job of public toilet attendants efficient.

The study intends to assess the air quality of public toilets only. The sensor to be used is MQ135, a sensor capable of detecting Carbon Dioxide, Ammonia, Mono-nitrogen oxide, and other harmful gasses present in public toilets. The sensor will give the overall air quality in PPM or parts per million, not the gasses' discrete presence. The system will be built as a project prototype and will be used to gather data.

\section{MATERIALS AND METHODS}

\subsection{Conceptual Framework}

A conceptual framework in Figure 1 was created based on the gathered related studies. Indoor air, the study's primary focus, and air quality sensors will be the inputs. The creation of the hardware and software ad wireless signa transmission would be part of the process to develop a system that would assess the air quality inside the public toilet and that that would recognize the attendant who attended the toilet at a specific time.

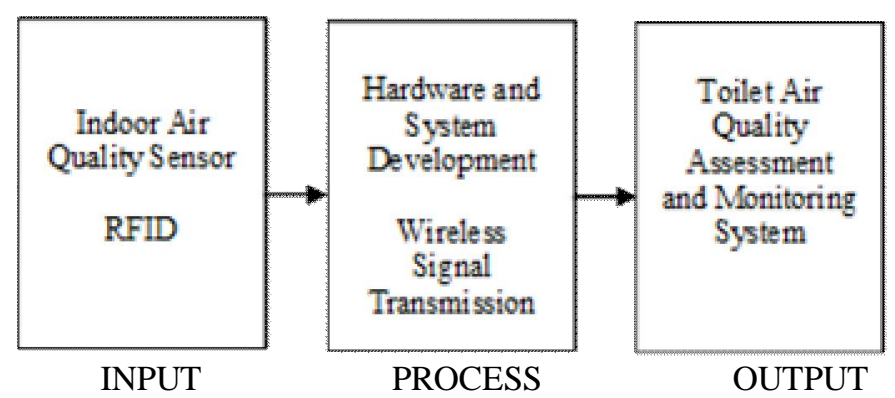

Figure 1: Conceptual Framework

\subsection{System Development and Block Diagram}

A trade-off analysis was conducted to come up with a wellorganized output. The system is mostly composed of gas sensors to detect the gas present in the toilet, a microcontroller, and a computer system to help control the process, WLAN for data transmission. The gas sensor used is MQ135, an air quality sensor capable of detecting toxic gases 
like sulfide, ammonia gas, benzene, and carbon dioxide, prevalent in public toilets. A computer system with a touch screen LCD was installed in the toilet where the Arduino UNO, sensors, and RFID are attached. It controls most of the processes in the system. It has an easily accessible software and hardware platform and compatible with most of the sensors. WLAN and Wifi Router was used for data transmission. For the server and database, a laptop was used. The hardware wherein the LED, buzzer, RF Transceiver module, and RFID for toilet attendant registration is connected.

The block diagram in Figure 2 provides an outline of the system's interaction to its components. The main blocks represent the interconnected processes. For the air quality assessment and monitoring part, MQ135 gathered the air quality sample, and together with the data from the RFID, it was transmitted to the server with the use of WLAN. An additional feature of the system is the user feedback wherein toilet users will express toilet experience by pressing the touch screen LCD. The data from the user feedback was also transmitted wirelessly.

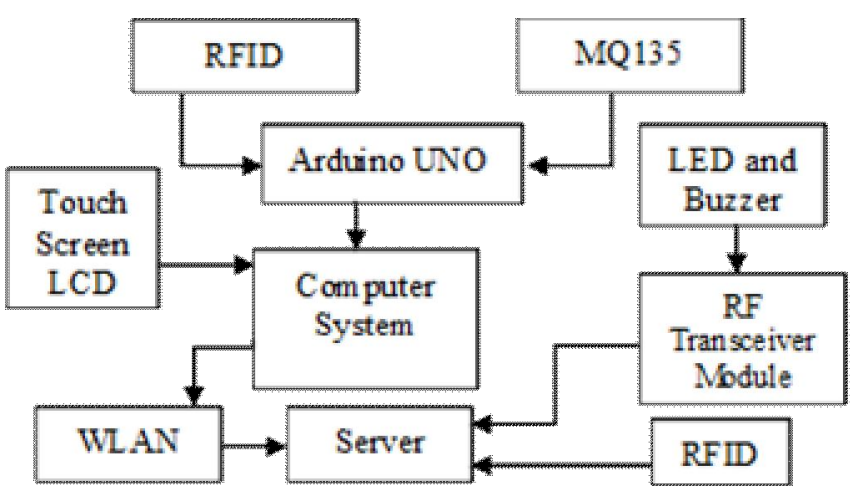

Figure 2: Block Diagram

\subsection{Calibration of Sensors}

The sensor was calibrated according to the formulation of David Gironi, and the sensitivity graph of MQ135 shown in Figure 3 wherein the sensor's resistance ratio (RS/RO) and the concentration of gas in PPM are connected as a power function. From this formulation, the gas' scaling factor (a) and exponential factor (b) were derived using Power Regression Analysis with the corresponding value of 121.4517 (a) and -2.78054 (b) [18]. Arduino produces output in an analog type, which is not a good function for reading the concentration of gas. The details must be translated to PPM values (parts per million). The conversion of the analog values $(0-1023)$ to the corresponding voltage values (Vout)(0-5V) was carried out using:

$V_{\text {out }}=\frac{\text { Analog Value } \times 5}{1023}$
The resistance of sensor (RS) is defined in the datasheet of MQ135 as:The resistance of sensor (RS) is defined in the datasheet of MQ135 as:

$$
\begin{aligned}
& R_{g}=\left(\frac{V_{C E}}{V_{\text {out }}}-1\right) \times R_{L} \\
& R_{g}=\left(\frac{1023}{\text { Analog Value }}-1\right) \times R_{L}
\end{aligned}
$$

Sensitivity Characteristics Graph shown in (Figure 3) had been used to collect $\mathrm{CO} 2$ data. Gironi's Power function was applied for this and with the scaling and the exponential factor, the gas' concentration was calculated as:

ppm $=a *\left(\frac{R_{s}}{R_{Q}}\right)^{\wedge} b$

All formulas and values were loaded in the MQ135 Arduino library for precise sensor readings.

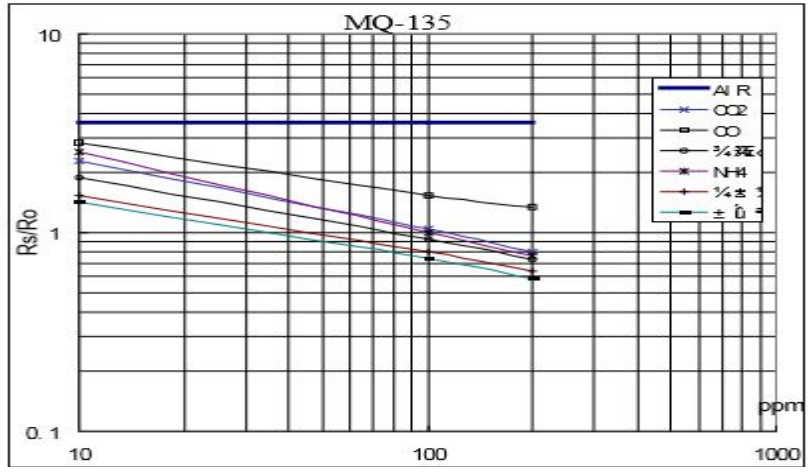

Figure 3: Sensitivity Characteristics Graph of MQ135 [19]

\subsection{Testing Procedures}

The system was set up in a male toilet composed of three cubicles and three urinals with the hardware installed in an area accessible to both the toilet attendants and the toilet users. Sensors were placed on the urinal area and each cubicle.

As described by Figure 4, the adjusted sensor allowed the analog output voltage relational to the air concentration in Parts Per Million (ppm). The data obtained were transmitted to the server through a wireless local area network. The server's received data was assessed and saved by the system, and corresponding functions were executed. 


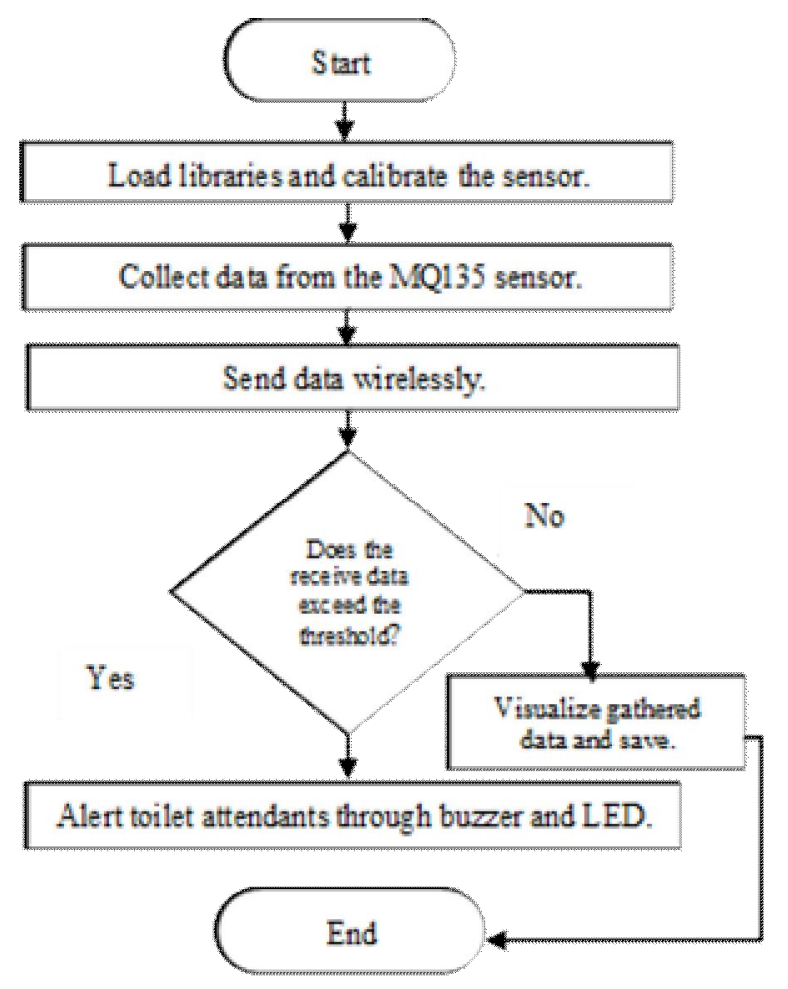

Figure 4: Testing Procedures for Air Quality Assessment and Monitoring

The testing procedure for the recognition of toilet attendants during cleaning time is presented in Figure 5. RFID's sensitivity was checked first to get the exact data. The data was transmitted wirelessly, and the server saved the received data in the system's database.

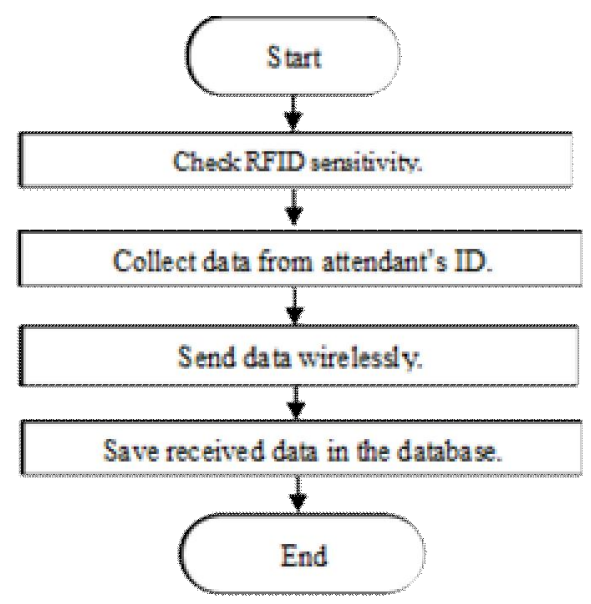

Figure 5: Testing Procedures for Toilet Attendant's Recognition

A good general measure of indoor air quality can be obtained through the proportion of $\mathrm{CO} 2$ or Carbon Dioxide present in this indoor air [18]. The most common used for indoor air quality and ventilation rate monitoring is Carbon Dioxide [19].
Table 1 shows the characterization of indoor air quality dependent on the concentration of Carbon Dioxide provided by the Occupational Health and Safety Administration (OHSA) [20]. The same standards were given by The Wisconsin Department of Health Services and by other references gathered.

Table 1: IAQ Description Based From CO2 Concentration [20-22]

\begin{tabular}{|c|l|}
\hline $\begin{array}{l}\text { Concentration } \\
(\text { PPM })\end{array}$ & Description \\
\hline $250-400$ & $\begin{array}{l}\text { Good. Fresh Air, perfect conditions. } \\
\text { Background (normal) outdoor air level. }\end{array}$ \\
\hline$<1000$ & $\begin{array}{l}\text { Moderate. Typical level found in occupied } \\
\text { spaces with good air exchange. }\end{array}$ \\
\hline $1000-2000$ & $\begin{array}{l}\text { Air was viewed as stuffy and not clean. Level } \\
\text { associated with complaints of drowsiness and } \\
\text { poor air. }\end{array}$ \\
\hline $2000-5000$ & $\begin{array}{l}\text { People with respiratory conditions can get } \\
\text { cough, weak people can faint. Level associated } \\
\text { withheadaches, sleepiness, and stagnant, stale, } \\
\text { stuffy air. }\end{array}$ \\
\hline$>5000$ & $\begin{array}{l}\text { It suggests unusual air conditions in which } \\
\text { elevated amounts of certain gasses might still be } \\
\text { present. Toxicity or oxygen deficiency can } \\
\text { occur. This is the permissible exposure limit for } \\
\text { daily workplace. }\end{array}$ \\
\hline 40000 & $\begin{array}{l}\text { This degree is instantly unhealthy due to the } \\
\text { shortage and absence of oxygen. }\end{array}$ \\
\hline
\end{tabular}

For the system's accuracy in terms of toilet attendant's recognition and notification, the confusion matrix principle was applied. It was calculated by summing up all the true values divided by the total value of both true and false predictions [23-24]. The calculation is shown in Equation 1:

Accuracy $=\frac{T P+T N}{T P+T N+F N+F P} \times 100$

where Accuracy is the accuracy of the system in percentage, TP is True Positive, TN is True Negative, FN is False Negative, and FP is False Positive.

\section{RESULTS AND DISCUSSIONS}

\subsection{Graphical User Interface}

The software for both transmitter and server were developed using Visual Basic.Net programming language. It is a modern yet straightforward programming language compatible with most of the materials used in the system. Through this, the Graphical User Interface (GUI) of the system was created. 
The transmitter's GUI is shown in Figure 6. It is divided into two sections: the toilet attendants' login and user feedback. When the button in the rightmost part representing a "sad" reaction is pressed, the user will be redirected to a page to select the concern they encountered upon using the toilet.
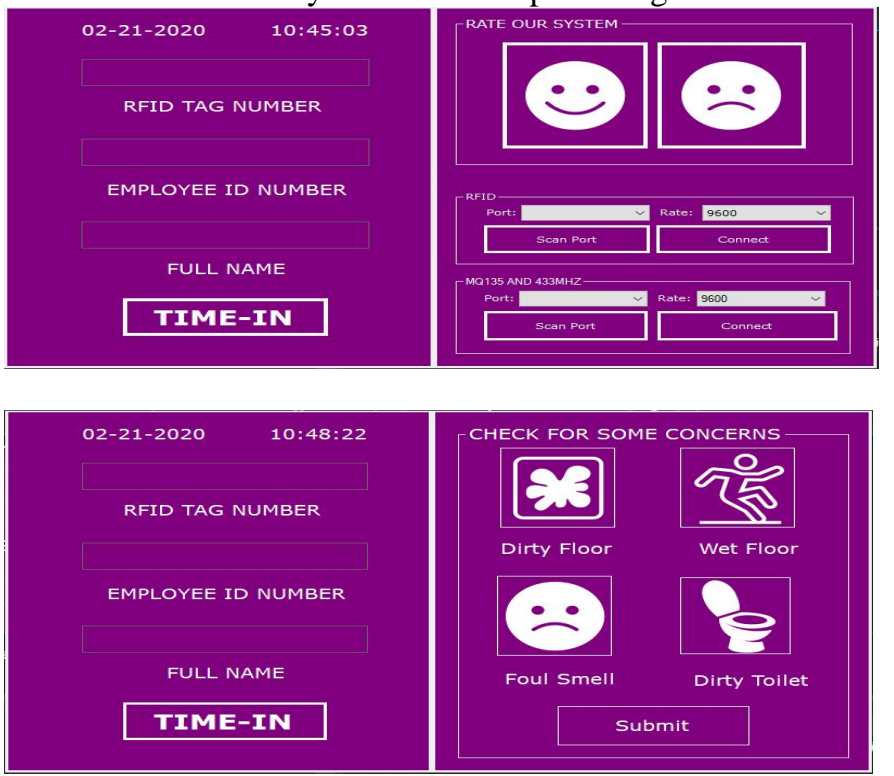

Figure 6: Transmitter GUI

Shown in Figure 7 is the "Home Menu" of the server. There are three buttons on the left side of the interface. The "PPM Monitoring" button, which is in the uppermost part, displays air quality inside the toilet and its corresponding index. The "Feedback" button displays the users' response to their toilet experience, which helps the toilet attendants evaluate the toilet's current condition. And lastly, the "Exit" button which closes the software when clicked.
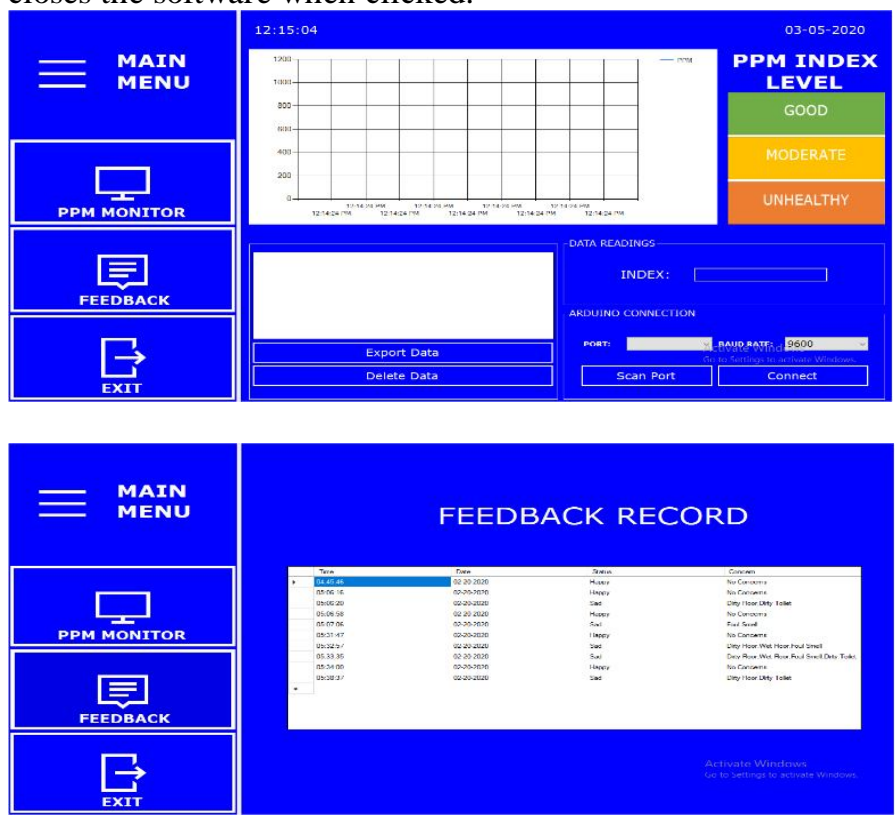

Figure 7: Server GUI
The toilet attendant's record is presented in Figure 8. The "Registration" button enables the admin to create and delete files. The "Time In/Time Out" button displays the time in and time out records of the toilet attendants.
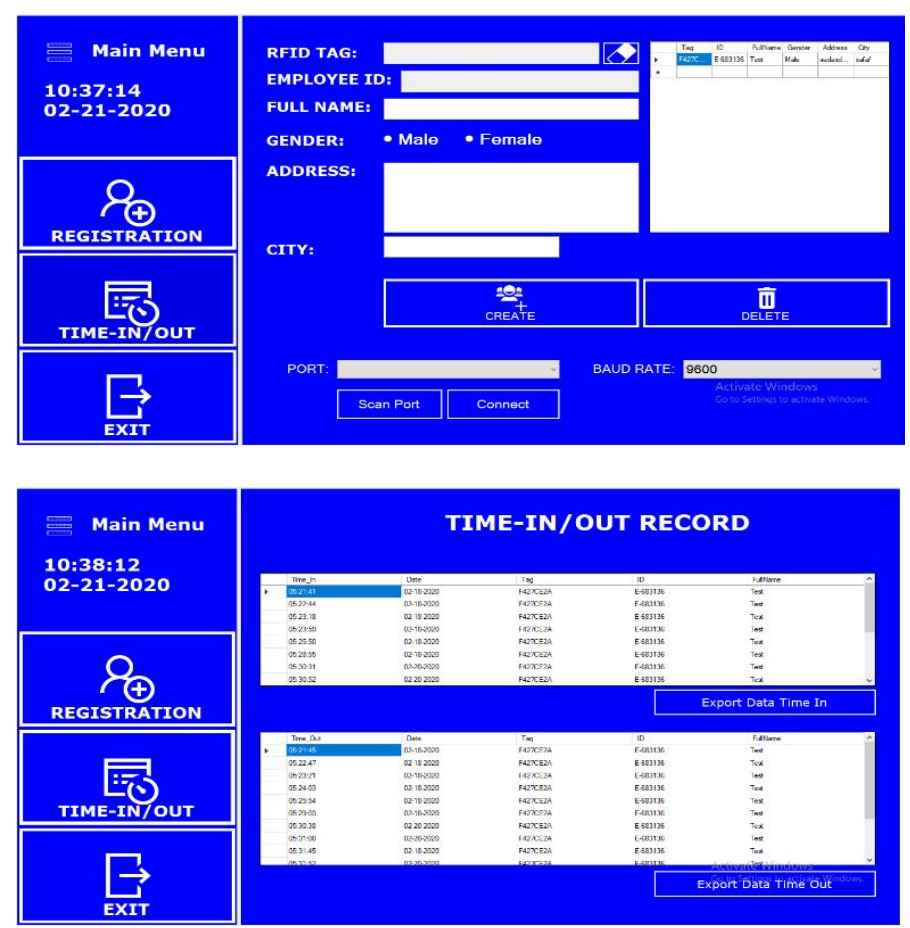

Figure 8: Toilet Attendant's Record GUI

\subsection{Functionality Test}

Hardware setup for the transmitter and server is shown in Figure 9 and Figure 10. All sensors were positioned in respective places. The air quality measure transmitted by the setup was the average air quality collected by the sensors and was calculated using the equation:

$A Q=\frac{A+B+C+U}{4}$

where AQ is the average air quality in PPM, A is the air quality from the first cubicle, $\mathrm{B}$ from the second cubicle, $\mathrm{C}$ from the third cubicle and $U$ from the urinal area. The server was set up around 20 meters from the transmitter. The data received was then evaluated through a table with the PPM concentration and the time as variables.

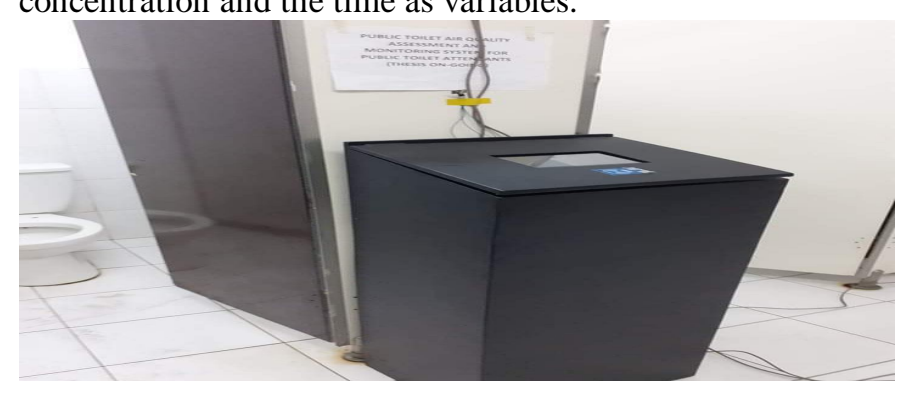

Figure 9: Transmitter Hardware Setup 


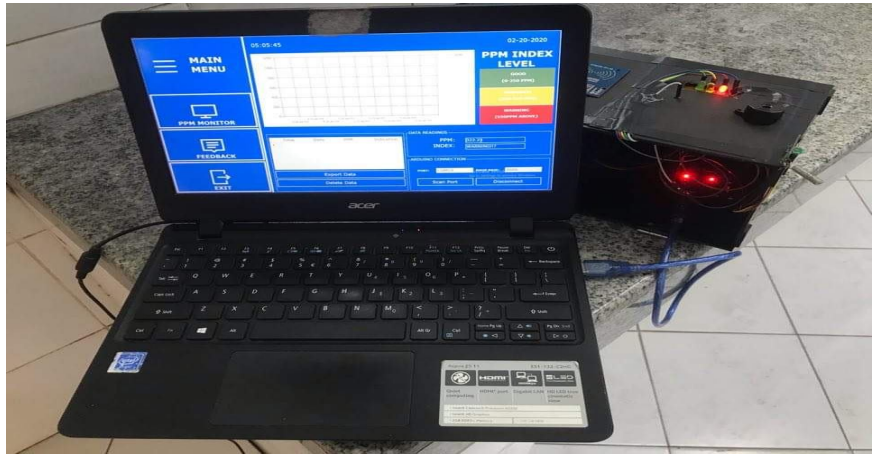

Figure 10: Server Hardware Setup

\subsection{Data Analysis}

From the functionality test conducted, realistic data from the system were gathered. Figure 11 shows the data obtained during the conduct of the functionality test. The graph represents fluctuating data meaning the air quality inside the toilet changes from time to time. At Day 1, all data gathered on the first hour were below the acceptable level. The toilet was cleaned an hour before the test, and the smell inside was not awful. But on the test's succeeding hours, the measure of air quality increased until it exceeded the acceptable benchmark of 1000 PPM. On day 2, most values outdid the sustainable value of air quality. On the third day of testing, all of the air quality values were more than the satisfactory range. The toilet smell during Day 2 and Day 3 trial was quite disturbing. The system displayed a "warning" indication on those values of 1000 PPM and above, and these statistics made the alarm device on the server's end to buzz.
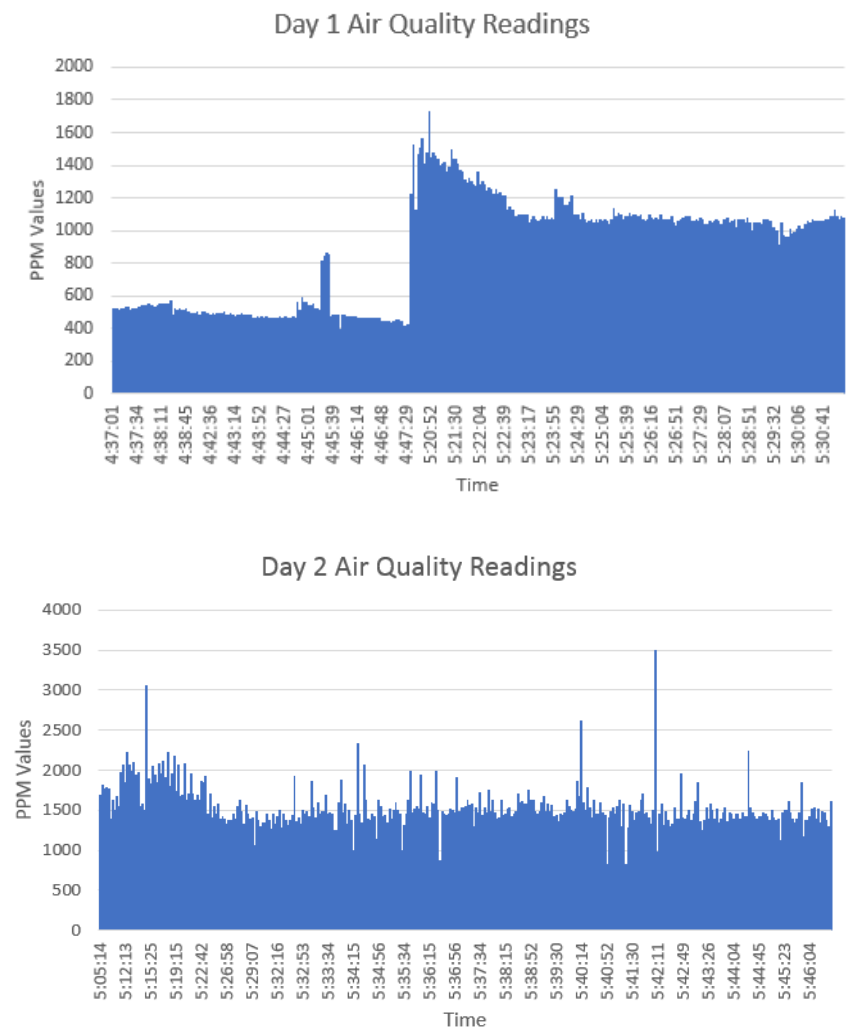

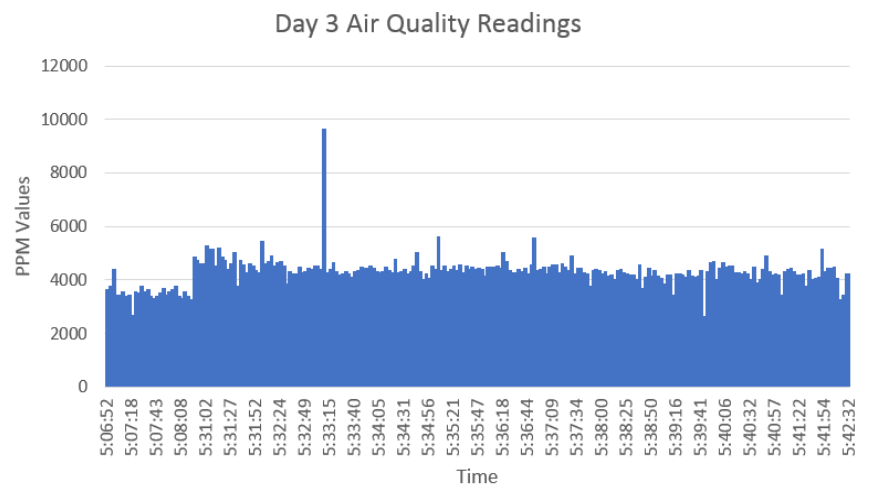

Figure 11: Air Quality Data

Table 2 shows the Confusion Matrix illustrating the results of gathering air quality data. There were 45 air quality values assessed and interpreted in which 38 were above the acceptable range, 4 for good, and 3 for moderate. The system displayed the corresponding interpretation of these values as the server received it, resulting in a $96.33 \%$ accuracy. On the other hand, Table 3 presents the result in the notification part of the system. With the equation of Confusion Matrix, it is revealed that the accuracy for the notification part of the system is $96 \%$, wherein the notification device functioned respectively with the received air quality data.

Table 2: Confusion Matrix For Air Quality Values

\begin{tabular}{|c|c|c|c|c|c|}
\hline & \multicolumn{4}{|c|}{ Predicted } \\
\hline & & $\begin{array}{l}\text { Good } \\
\text { (4) }\end{array}$ & $\begin{array}{l}\text { Moderate } \\
\text { (3) }\end{array}$ & $\begin{array}{l}\text { Unhealthy } \\
\text { (38) }\end{array}$ & $\begin{array}{l}\text { Unknow } \\
\mathrm{n}\end{array}$ \\
\hline \multirow[b]{3}{*}{ 吾 } & Good & 4 & 0 & 1 & 0 \\
\hline & Moderate & 0 & 3 & 3 & 0 \\
\hline & $\begin{array}{l}\text { Unhealth } \\
\mathrm{y}\end{array}$ & 0 & 0 & 34 & 0 \\
\hline \multicolumn{2}{|c|}{ TOTAL } & 4 & 3 & 38 & \\
\hline \multicolumn{2}{|c|}{ ACCURACY } & $100 \%$ & $100 \%$ & $89.47 \%$ & \\
\hline \multicolumn{2}{|c|}{$\begin{array}{l}\text { OVERALL } \\
\text { ACCURACY }\end{array}$} & \multicolumn{3}{|c|}{$91.11 \%$} & \\
\hline
\end{tabular}

Table 3: Confusion Matrix For The Notification Device

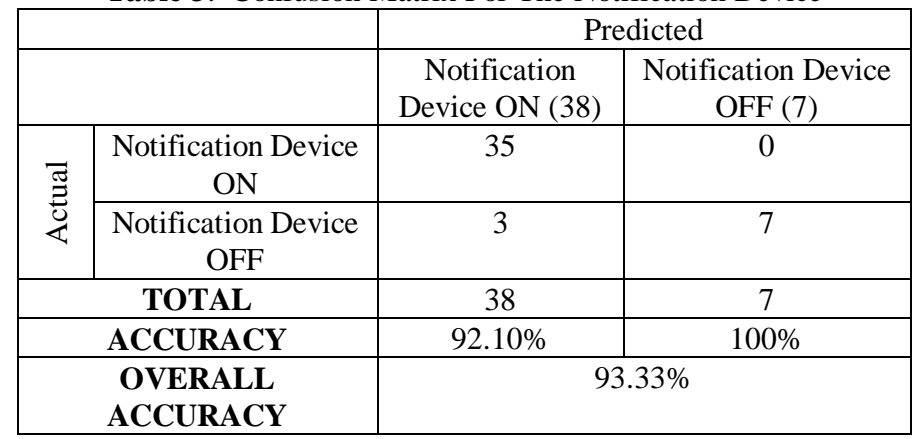


Table 4 illustrates the functionality test results in terms of toilet attendants' time in and time out. There were 10 time-in trials and 10 time-out trials conducted in this test. With the same equation, it was found out that the system has $100 \%$ accuracy in this function.

Table 4: Confusion Matrix For Toilet Attendants' Login

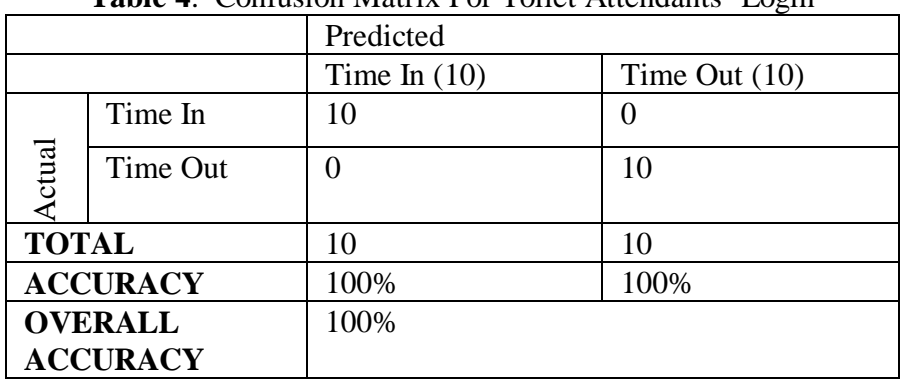

\section{CONCLUSIONS AND FUTURE WORKS}

Generally, the research conducted was successful in designing and implementing a toilet air quality assessment and monitoring system. The methods and materials used were able to gather real-time air quality data. These values were then identified following the reference air quality standards. The system was able to give notification regarding the toilet status based on the received data. It was also able to recognize the registered toilet attendant who attended the toilet at a particular time. The system's performance is efficient and user-friendly, and its functionality is highly comparable to the expensive existing systems. The whole system is extremely useful in monitoring air quality inside public toilets since it delivers real- time data. It can also evaluate the current status of the bathroom, which significantly affects the toilet user experience.

The system can be enhanced by using sensors that will accurately identify air pollutants inside the toilet. Other researchers with related studies may also examine other parameters affecting toilet users, impacting air quality such as ventilation, temperature, and humidity. For a more extended range of data communication, other wireless data transmission device with higher bandwidth may also be used.

\section{REFERENCES}

1. J. M. Seguel, R. Merrill, D. Seguel, and A. C. Campagna, "Indoor Air Quality," Am. J. Lifestyle Med., 2017, doi: $10.1177 / 1559827616653343$.

2. K. W. Tham, "Indoor air quality and its effects on humans-A review of challenges and developments in the last 30 years," Energy Build., 2016, doi: 10.1016/j.enbuild.2016.08.071.

3. P. Ifunanya Ohagim, G. Michael Ikon, P. Chika Matthew, and G. Amarachi Ohagim, "Microbiological
Assessment of Indoor Air in Public Toilets across Selected Motor Parks in Owerri Metropolis, Nigeria," J. Microbiol. Exp., 2017,

doi: 10.15406/jmen.2017.05.00166.)

4. R. Pitarma, G. Marques, and F. Caetano, "Monitoring indoor air quality to improve occupational health," in Advances in Intelligent Systems and Computing, 2016, vol. 445, pp. 13-21, doi: 10.1007/978-3-319-31307-8_2.

5. A. C. K. Lai, T. F. Tan, W. S. Li, and D. K. M. Ip, "Emission strength of airborne pathogens during toilet flushing," Indoor Air, 2018, doi: 10.1111/ina.12406.

6. M. Telejko, "Attempt to Improve Indoor Air Quality in Computer Laboratories," Procedia Eng., 2017, doi: 10..1016/j.proeng.2017.02.134.R. A. Scholtz. The Spread Spectrum Concept, in Multiple Access, N. Abramson, Ed. Piscataway, NJ: IEEE Press, 1993, ch. 3, pp. 121-123.

7. G. M. Chitaru, A. Istrate, and T. Catalina, "Numerical analysis of the impact of natural ventilation on the Indoor Air Quality and Thermal Comfort in a classroom," in E3S Web of Conferences, 2019, doi: 10.1051/e3sconf/201911101023.

8. P. Carrer and P. Wolkoff, "Assessment of indoor air quality problems in office-like environments: Role of occupational health services," Int. J. Environ. Res. Public Health, 2018, doi: 10.3390/ijerph15040741.

9. K. Okokpujie, E. Noma-Osaghae, O. Modupe, S. John, and O. Oluwatosin, "A smart air pollution monitoring system,” Int. J. Civ. Eng. Technol., 2018, doi: 10.31142/ijtsrd18191.

10. N. Kaur, R. Mahajan, D. Bagai, and P. G. Student, "Air Quality Monitoring System based on Arduino Microcontroller," Int. J. Innov. Res. Sci. Eng. Technol. (An ISO Certif. Organ., 2016, doi: 10.15680/IJIRSET.2015.0506018.

11. P. Pal, R. Gupta, S. Tiwari, and A. Sharma, "IOT Based Air Pollution Monitoring System,” Imp. J. Interdiscip. Res., 2017.

12. S. Brienza, A. Galli, G. Anastasi, and P. Bruschi, "A low-cost sensing system for cooperative air quality monitoring in urban areas," Sensors (Switzerland), 2015, doi: 10.3390/s150612242.

13. S. Kumar and A. Jasuja, "Air quality monitoring system based on IoT using Raspberry Pi," Proceeding - IEEE Int. Conf. Comput. Commun. Autom. ICCCA 2017, 2017, doi: 10.1109/CCAA.2017.8230005.

14. T. M. Rachovski, I. M. Ivanov, E. N. Hadzhikolev, and S. I. Hadzhikoleva, "Air pollution monitoring system," Int. J. Innov. Technol. Explor. Eng., 2019, doi: 10.35940/ijitee.K2067.0981119.

15. S. Dhingra, R. B. Madda, A. H. Gandomi, R. Patan, and M. Daneshmand, "Internet of things mobile-air pollution monitoring system (IoT-Mobair)," IEEE Internet Things J., 2019, doi: 10.1109/JIOT.2019.2903821. 
16. Chen, S. C. (2019). Relatively Low-Cost Personal Mobile Device for PM2.5, CO, and $\mathrm{CO} 2$ Measurements Coupled with Positioning, Cellular Network Cloud Computing and Storage, and Web Application UI. International Journal of Advanced Trends in Computer Science and Engineering, 8(5), 2068-2075. doi:10.30534/ijatcse/2019/34852019

17. R, K. (2020). Forecasting of the Air Pollution Based on Meteorological Data and Air Pollutants using Deep Learning: A Novel Review. International Journal of Advanced Trends in Computer Science and Engineering, 9(1), 801-807. doi:10.30534/ijatcse/2020/115912020

18. Kalra, Vandana \& Baweja, Chaitanya \& Simmarpreet, Dr \& Chopra, Supriya. (2016). Influence of Temperature and Humidity on the Output Resistance Ratio of the MQ-135 Sensor. International Journal of Computer Science and Software Engineering. 6. 2277.

19. MQ $135 \quad$ Data Sheet https://datasheetspdf.com/pdffile/605076/Hanwei/MQ-1 $35 / 1$

20. (2019).Carbon Dioxide By The Wisconsin Department of Health Services.[online]Available: https://www.dhs.wisconsin.gov/chemical/carbondioxide .htm

21. Pietrucha, T. (2017). Ability to determine the quality of indoor air in classrooms without sensors. In E3S Web of Conferences (Vol. 17). EDP Sciences. https://doi.org/10.1051/e3sconf/20171700073

22. (2016). Carbon Dioxide Detection and Indoor Air Quality Control By The Occupational Health and Safety. [online]Available:

https://ohsonline.com/articles/2016/04/01/carbon-dioxid e-detection-and-indoor-air-quality-control.aspx

23. R. A. D. Esmeralda, R. J. A. Regalado, G. I. J. F. Rosa and R. S. Pangantihon, "Automated Hollow Tile Floor Detector Using Fast Fourier Transform," 2019 IEEE 11th International Conference on Humanoid, Nanotechnology, Information Technology, Communication and Control, Environment, and Management ( HNICEM ), Laoag, Philippines, 2019, pp. 1-5, doi: 10.1109/HNICEM48295.2019.9072856.

24. Tito C. Lim, Jaedy O. Torregosa, Aubrey Rose A. Pescadero, and Rodrigo S. Pangantihon. 2019. De-husked Coconut Quality Evaluation using Image Processing and Machine Learning Techniques. In Proceedings of the 2019 6th International Conference on Bioinformatics Research and Applications (ICBRA '19). Association for Computing Machinery, New York, NY, USA, 28-33.

DOI:https://doi.org/10.1145/3383783.3383789 